\title{
Erosion resistance of copper/alumina composite
}

\author{
Š. Kavecký*, P. Štefánik, K. Iždinský, Š. Nagy, P. Šebo, N. Beronská, A. Opálek \\ Institute of Materials and Machine Mechanics, Slovak Academy of Sciences, \\ Račianska 75, 83102 Bratislava, Slovak Republic
}

Received 6 June 2015, received in revised form 23 October 2015, accepted 9 November 2015

\begin{abstract}
The ablation resistance of $\mathrm{Cu}$ and $\mathrm{Cu} / \mathrm{Al}_{2} \mathrm{O}_{3}$ subjected to 200 spark discharges was compared in this work. It appears that the volume lost in the course of sparking was 6 times higher for $\mathrm{Cu}$ than for $\mathrm{Cu} / \mathrm{Al}_{2} \mathrm{O}_{3}$ composite. Linear dependences of the amount of loss material on the number of electrical discharge analytical cycles for $\mathrm{Cu} / \mathrm{Al}_{2} \mathrm{O}_{3}$ composite material and pure copper were determined. $\mathrm{Cu} / \mathrm{Al}_{2} \mathrm{O}_{3}$ composite failure mode includes the evaporation as well as melting of constituents. The interaction of spark with the substrate is quite a discrete process strongly affected by local chemistry (composition). It results in irregular phases with respect to morphology as well as composition.
\end{abstract}

K e y w or d s: ablation resistance, copper matrix, alumina preform

\section{Introduction}

The copper/alumina composite can be used in many industrial applications due to its relatively high electrical and thermal conductivities and excellent wear resistance properties. The composite typically consists of two pure phase materials forming interconnected networks of solid phases with minimum porosity. For metal-ceramic interpenetrating networks, the metallic phase is usually the one that is filling the cells of a porous ceramic preform. Each phase contributes with its properties to the multifunctional characteristics of the whole structure. The ceramic has high hardness and wear resistance whereas the metal improves fracture toughness and thermal conductivity. The interpenetrating metal-ceramic composites due to superior properties may have remarkable applicability in different sectors of industry [1].

Many of liquid metals do not wet oxide ceramic surfaces. Some elements form a reactive system with alumina $(\mathrm{Ni}, \mathrm{Si}, \mathrm{Fe}$ and $\mathrm{Al})$. However, the large group of elements does not react with alumina $\mathrm{Pb}, \mathrm{Sn}, \mathrm{In}$, $\mathrm{Ga}, \mathrm{Ag}, \mathrm{Au}$ and $\mathrm{Cu}[2,3]$. Therefore, due to poor wettability of most metals on oxide ceramics, the penetration of molten metal into ceramic preform must be accomplished by squeeze casting method [4] or gas pressure infiltration [5]. Wettability of copper on alu- mina is extremely low (contact angle varying between $124^{\circ}$ and $\left.170^{\circ}[3,6]\right)$. Moreover, due to the difference in coefficients of thermal expansion the large residual stresses in the composite are generated $[7,8]$.

Erosion caused by the interaction of an electrical discharge with the surface of electrodes is a fundamental process occurring in many technical requirements. Several possible approaches, how to reduce the erosion rate of electrodes, are on hand. These include the control of electrode materials, reduction of the grain size of metallic materials, control of the chemistry of plasma generating medium, cooling, etc. From all possible approaches, modification of materials belongs to the most effective and preferable [9].

Due to its ability to excite many elements, the spark discharge has been for a long time used as an excitation source for spectrochemical analysis, commonly called as spark discharge plasma optical emission spectrometry (SD-OES) [10]. SD-OES is based on the ablation of sample material by electrical sparks plasma.

In SD-OES spectrometer excitation is produced by the energy of the electrical discharge between the sample and electrode. A spark produces energy into the material that increases the material temperature very locally even over the boiling point. Thus, a part of the electrode material is melted and sometimes evap-

\footnotetext{
*Corresponding author: tel.: +421 0249268 281; e-mail address: ummskave@savba.sk
} 
orated. Several alternative mechanisms have been proposed to explain the surface modifications associated with sparking, such as thermoionic electron emission, photoinduced ionization, sputtering, evaporation, and oxide removal [11-14]. It remains unclear which of them are truly active and what are the ranges of their applicability [12].

Electrical discharge in spectrometer used in this work is a very complicated process. Thermal energy is provided in the form of electrical pulses with short duration (in $\mu$ s scale) with the frequency of hundreds Hz. The spark strikes the electrode, and electrical energy is transformed into thermal energy, causing local evaporation of electrodes as in laser ablation. Electrical breakdown as a partial step in an electrical discharge is accompanied by the formation of a thermal plasma channel between electrodes leading to their erosion. The resulting plasma temperatures $(\sim 5000 \mathrm{~K})$ effectively remove sample material (ablation) and excite the constituent atoms. The breakdown corresponds to the formation of a conductive channel between electrodes via streamer mechanism.

No erosion studies on $\mathrm{Cu} / \mathrm{Al}_{2} \mathrm{O}_{3}$ composite with interpenetrating networks have been published until now. Only some properties of this type of composite have been discussed so far $[7,8,15-18]$.

This paper is focused on the study of ablation of $\mathrm{Cu}$ and $\mathrm{Cu} / \mathrm{Al}_{2} \mathrm{O}_{3}$ composite subjected to spark discharge using SD-OES analyser.

\section{Experiment}

Copper/alumina composite was prepared by pressure infiltration of alumina preform by pure copper at $1200^{\circ} \mathrm{C}$ in $\mathrm{Ar}$ atmosphere at $5 \mathrm{MPa}$ during $15 \mathrm{~min}$. This material has been originally developed within 7FP project MATRANS oriented on the development of novel metal-ceramic functionally graded materials for aerospace and automotive applications. The alumina preform was prepared in the Technical University Darmstadt, Germany. The initial materials were alumina powder Almatis HVA FG with mean particle diameter $5.3 \mu \mathrm{m}$ and rice starch $(5.0 \mu \mathrm{m})$. A preform with a porosity of $59.0 \%$ was prepared via mixing of two homogeneous slurries followed by casting, drying, pyrolysing and sintering [18].

The erosion test was performed with SD-OES analyser (SPECTROMAXx, fy SPECTRO) at an overpressure of Ar with flow rate $3.51 \mathrm{~min}^{-1}$. In this study fully digital plasma generator SPECTRO was applied, that supplies and maintains constant plasma energy at generating pulse electric sparks with the frequency of $300 \mathrm{~Hz}$. The experiment was described in detail by Kavecký et al. [19].

Thousands of sparks were generated during one analytical cycle. A diagram of a spark stand (electrode

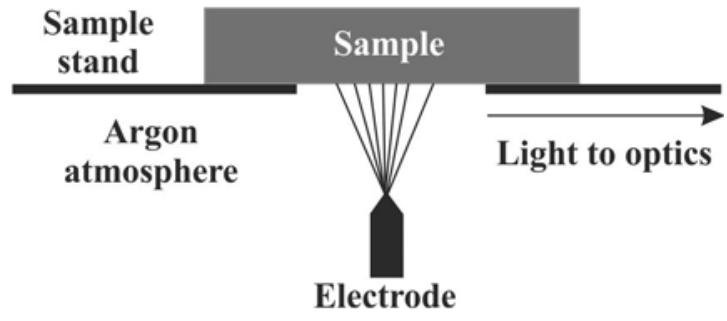

Fig. 1. Diagram of a spark stand (electrode and sample geometry, the diameter of the hole below sample is $10 \mathrm{~mm}$ ).

and sample geometry) is presented in Fig. 1. It illustrates the conventional "point-to-plane" configuration (electrode to sample). The sample is the cathode and the counter conical shape anode with the tip angle of 60 degrees made of tungsten.

The dependence of overall loss of weight with the number of electrical discharge analytical cycles was determined. The weight of composite and for comparison of pure copper after each ten cycles was measured with a digital balance Sartorius, which resolution is $0.01 \mathrm{mg}$, and compared to its initial weight before ablation. The corresponding loss of volume of ablated material was calculated by dividing the value loss of weight by density of composite. The morphology, microstructure and the composition of the examined specimens were spotted by a scanning electron microscopy (SEM) using a JEOL JSM 6610 microscope combined with an energy dispersive X-ray spectroscopy (EDS). Some surfaces of composite were etched in an aqueous solution of nitric acid (32.5 vol.\% $\left.\mathrm{HNO}_{3}\right)$.

\section{Results and discussion}

Copper based composites due to the implication of non-wetting alumina by liquid copper can be prepared by pressure infiltration of molten metal into a preform created from particles or fibres of suitable dimensions and useful porosity. Open porosity of the preform and density of copper - alumina composite were determined by Archimedes method. It was found out that copper fills in $95 \%$ of accessible leeks. Volume contribution of copper was consequently $\sim 56.1 \%$. Figure 2 confirms that copper matrix homogeneously penetrated into the preform. Figure 2 presents beside the composite microstructure also the EDS elemental mapping revealing the distribution of $\mathrm{Cu}, \mathrm{Al}$, and $\mathrm{O}$.

The aim of this work was to reveal and compare the ablation resistance of $\mathrm{Cu} / \mathrm{Al}_{2} \mathrm{O}_{3}$ composite subjected to spark discharge ablation process with that of pure copper metal. The amount of ablated material in volume units (cubic $\mathrm{mm}$ ) in dependence on a number of electrical discharge analytical cycles for 

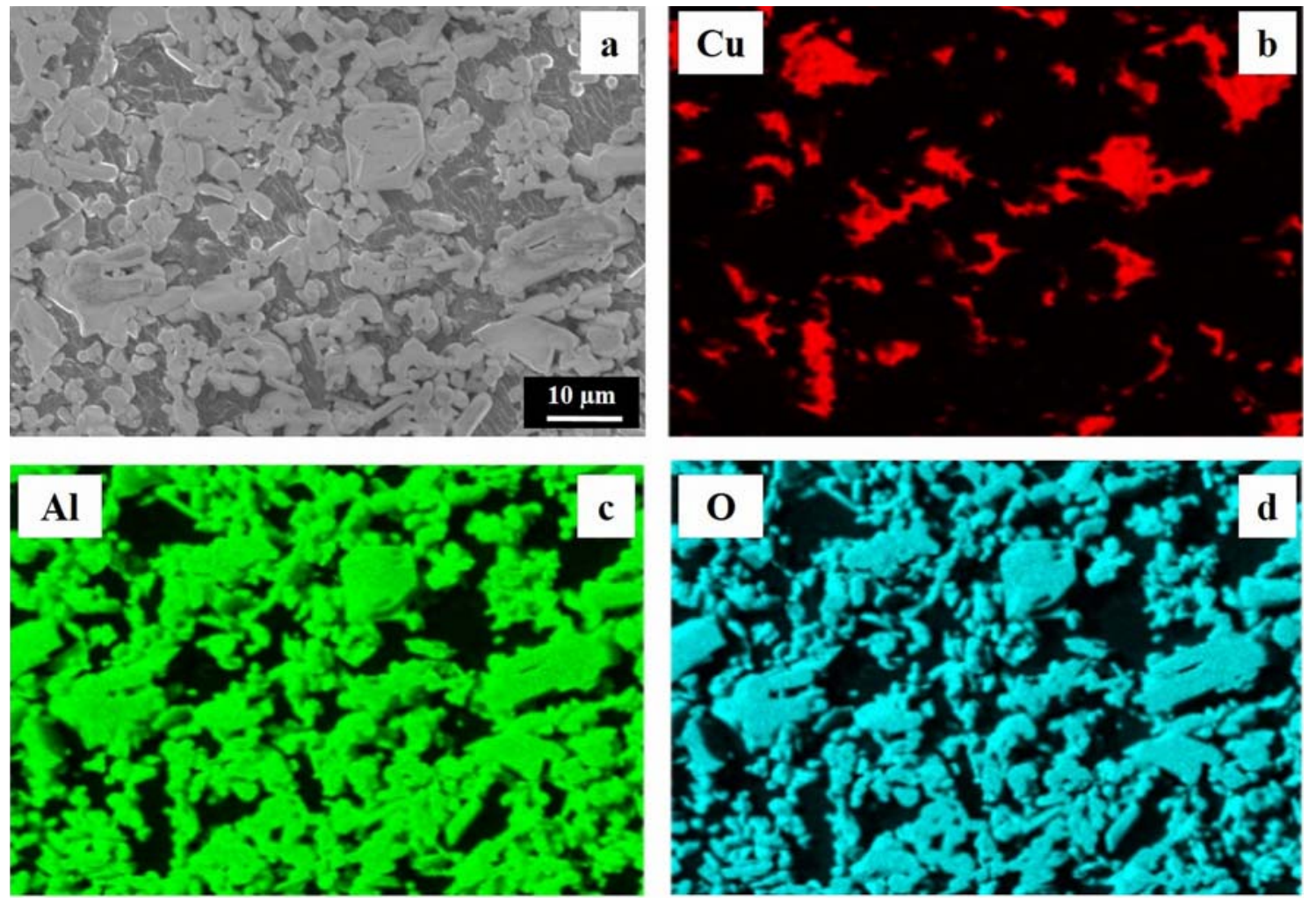

Fig. 2. SE micrographs of $\mathrm{Cu} / \mathrm{Al}_{2} \mathrm{O}_{3}$ (a) and corresponding X-ray elemental mapping revealing the distribution of $\mathrm{Cu}$ (b), $\mathrm{Al}(\mathrm{c})$ and $\mathrm{O}(\mathrm{d})$.

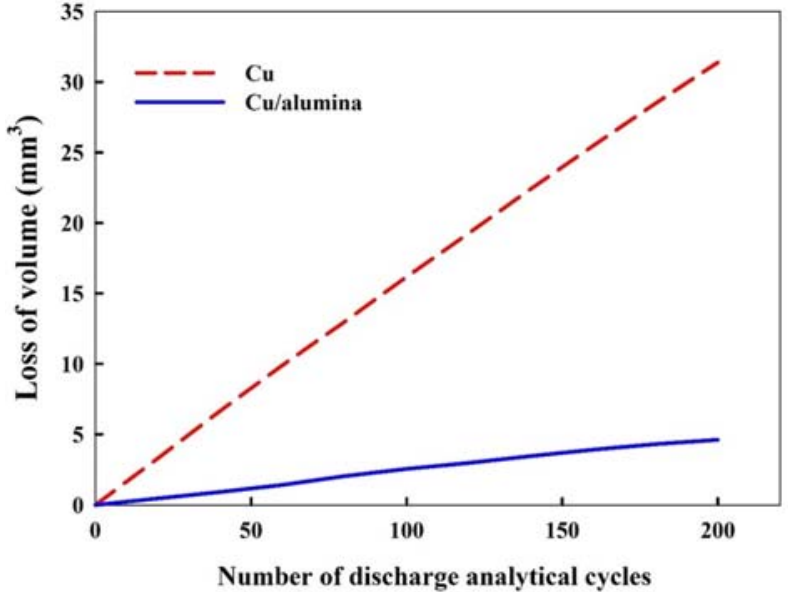

Fig. 3. Dependence of loss of volume vs. number of electrical discharge analytical cycles for $\mathrm{Cu} / \mathrm{Al}_{2} \mathrm{O}_{3}$ composite.

copper-alumina composite as well as for pure copper is shown in Fig. 3. It appears that the volume of ablated $\mathrm{Cu} / \mathrm{Al}_{2} \mathrm{O}_{3}$ composite is about 6 times smaller than in the case of pure copper.

The linearity of the dependence indicates that over the range of ablation resistance study approximately the same volume was ablated in each spark discharge analytical cycle. It also confirms the high homogen- eity of distribution of $\mathrm{Al}_{2} \mathrm{O}_{3}$ in the composite and the reproducibility of the method used. It appears that even lower number of spark discharge analytical cycles might be sufficient to estimate ablation resistance by this method in future. However, the most important result is the very positive contribution of $\mathrm{Al}_{2} \mathrm{O}_{3}$ component in copper to the improvement of its ablation resistance.

The morphology of sparked $\mathrm{Cu} / \mathrm{Al}_{2} \mathrm{O}_{3}$ composite surface as observed by SEM indicates similar failure as described more in [20].

First streamers attack inclusions and generate craters, subsequent streamers attack the adjacent inclusions because these are warmer, and they emit electrons more easily. At the end of all 200 electrical discharge analytical cycles a circular area with the diameter of about $10 \mathrm{~mm}$ (diameter is given by aperture of spark stand geometry) has been formed on the surface of tested samples (Figs. 4a, 5a).

The sparked-in spots on both observed samples $\left(\mathrm{Cu}\right.$ and $\mathrm{Cu} / \mathrm{Al}_{2} \mathrm{O}_{3}$ ) have a common pattern consisting of the zonal structure, i.e. central, middle and periphery (this structure is more markedly visible at $\mathrm{Cu} / \mathrm{Al}_{2} \mathrm{O}_{3}$ sample - Fig. 5c). This zonal structure was visible at samples already after 20 discharge cycles. Nevertheless, the depth of individual zones was lower. This is given by "point-to-plane geometry" that favours central discharges and a specific sample 


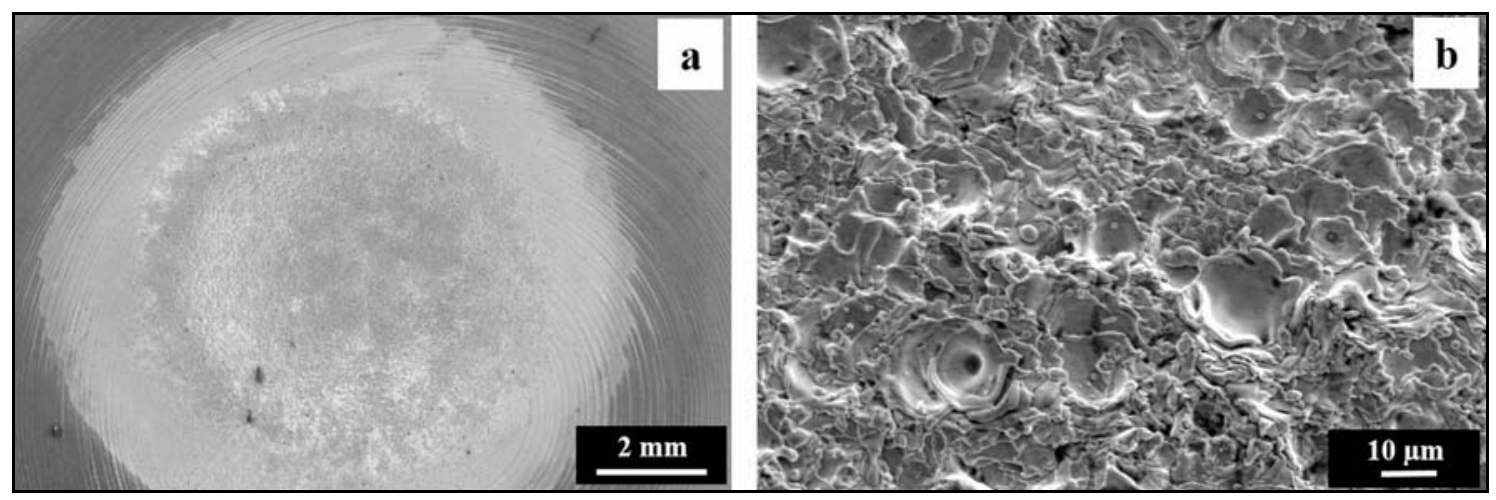

Fig. 4. SE micrographs of the surface morphology of $\mathrm{Cu}$ crater after 200 spark cycles.

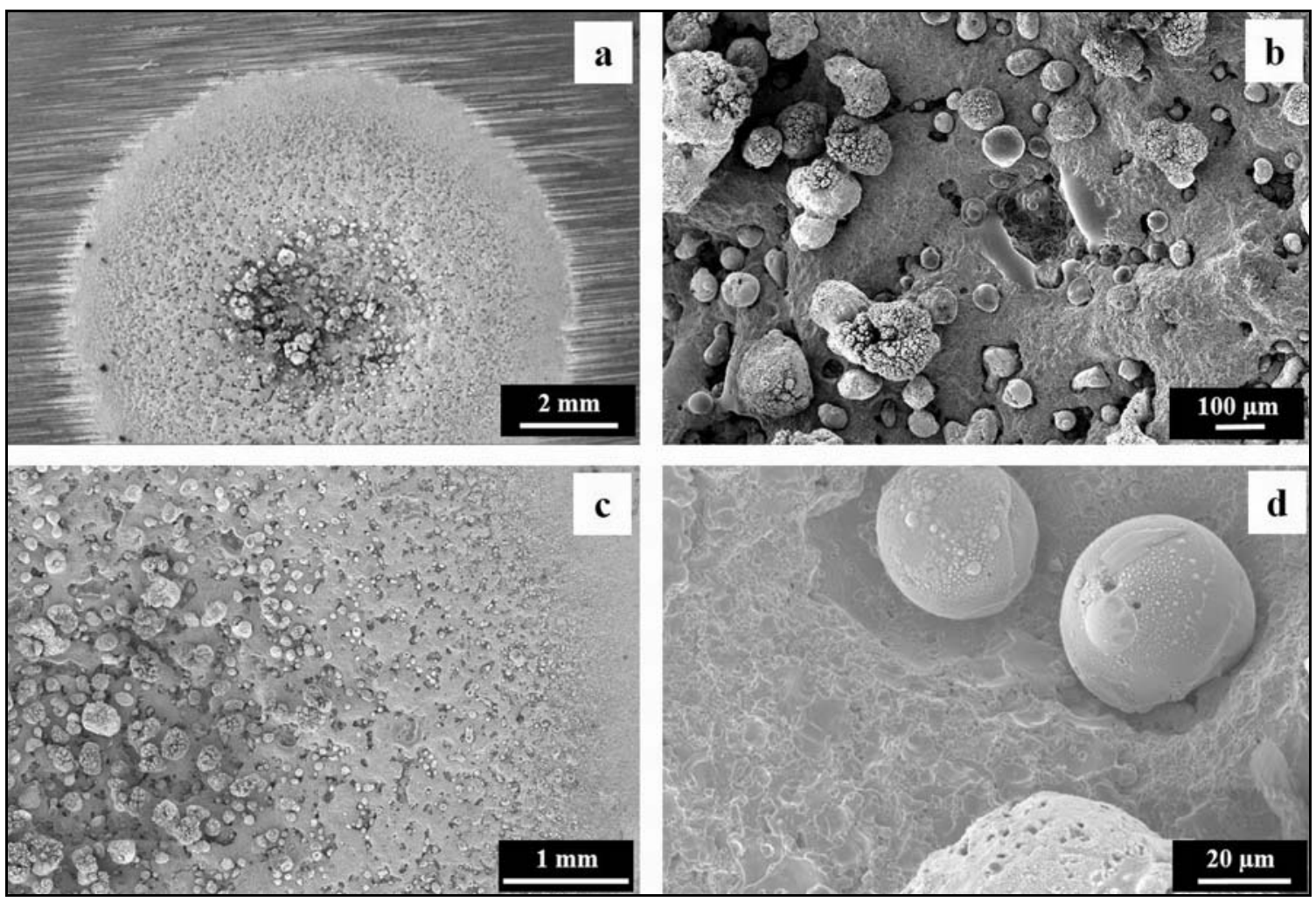

Fig. 5. SE micrographs of the surface morphology of $\mathrm{Cu} / \mathrm{Al}_{2} \mathrm{O}_{3}$ composite crater after 200 spark cycles: whole crater (a), zonal structure, i.e. central, middle and periphery of the crater (c) and details of central part of the crater at two magnifications $(\mathrm{b}, \mathrm{d})$.

erosion/etching (Fig. 6). Morphology of middle zone is similar as that of the central zone, however, created microstructure is affected by the lower density of sparks energy strike in this zone. The substance quantity evaporated/ejected during sparking is not the same for all sparked spots on the same specimen. The results of SEM investigation can be explained only by the streamer theory [20-22].

Figures $4 \mathrm{a}$ and $5 \mathrm{a}$ illustrate ablation zone of $\mathrm{Cu}$ and $\mathrm{Cu} / \mathrm{Al}_{2} \mathrm{O}_{3}$ samples after 200 cycles of spark discharge. The uniformity of the morphology of $\mathrm{Cu}$ crater is believed to be the result of isotropic mechanical and thermophysical properties of copper.

The plasma-surface interaction in sparks is typically observed to produce either single or multiple overlapping craters on surfaces and features that clearly resemble liquid blobs that have ejected from the crater and been frozen-in on the surface [23]. During applied electrical discharges for the continuance of analytical cycles, all these ranges of cratering were linked together as shown in Figs. 4b and 5b,d. This common feature was observed at craters of both materials, especially in regions with concentrated copper.

The shape of the crater caused by a single spark 


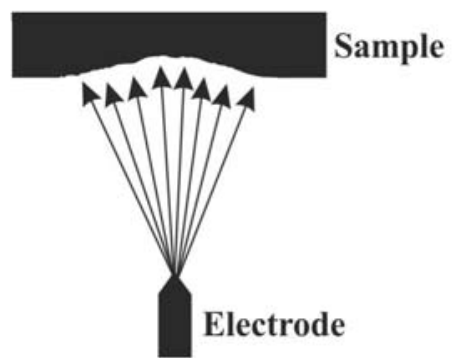

Fig. 6. Schematic image of ablation in the case of "pointto-plane geometry."

of quite high energy in the metallic $\mathrm{Al}$ with $\mathrm{Al}_{2} \mathrm{O}_{3}$ inclusions is described in [24]. The trace of the spark is a crater consisting of a hole surrounded by an elevated wall. It is reasonable to assume that the wall is a zone, where the spark energy is sufficient to melt the metal, but not intense enough to vaporise it. It is known that the spark craters dimensions vary with the sparks energy; the higher the single spark energy, the larger the spark crater. If an $\mathrm{Al}_{2} \mathrm{O}_{3}$ inclusion was hit, it vaporised, and the inclusion was removed from the sample surface. This, of course, is only true as long as the spark crater is larger than the inclusion.

The first spark events tend to hit inclusions, or more precisely, they tend to hit the border between metallic and the non-conducting phase. To ignite a spark, a high voltage is applied between the sample surface and counter tungsten electrode. If the sample surface were perfectly homogeneous and without any inclusions, every spark would hit exactly the point opposed to the tungsten electrode tip. The burned spot would have a very small diameter. In practice, the burn spot has a diameter of some millimetres. One of the reasons why spots, millimetres away from the counter electrode opposition are hit, can be found in the specific structure of the electrical field. If there is a non-conductive inclusion on the sample surface, there is a sharp metallic edge. At this edge, there is a higher concentration of the streamlines of the electrical field compared to those parts of the sample consisting of a pure metallic phase. A high density of the streamlines is created because they cannot end on the dielectric inclusion [24].

We supposed that the same ablation mechanism might be applied to understand the plasma-surface
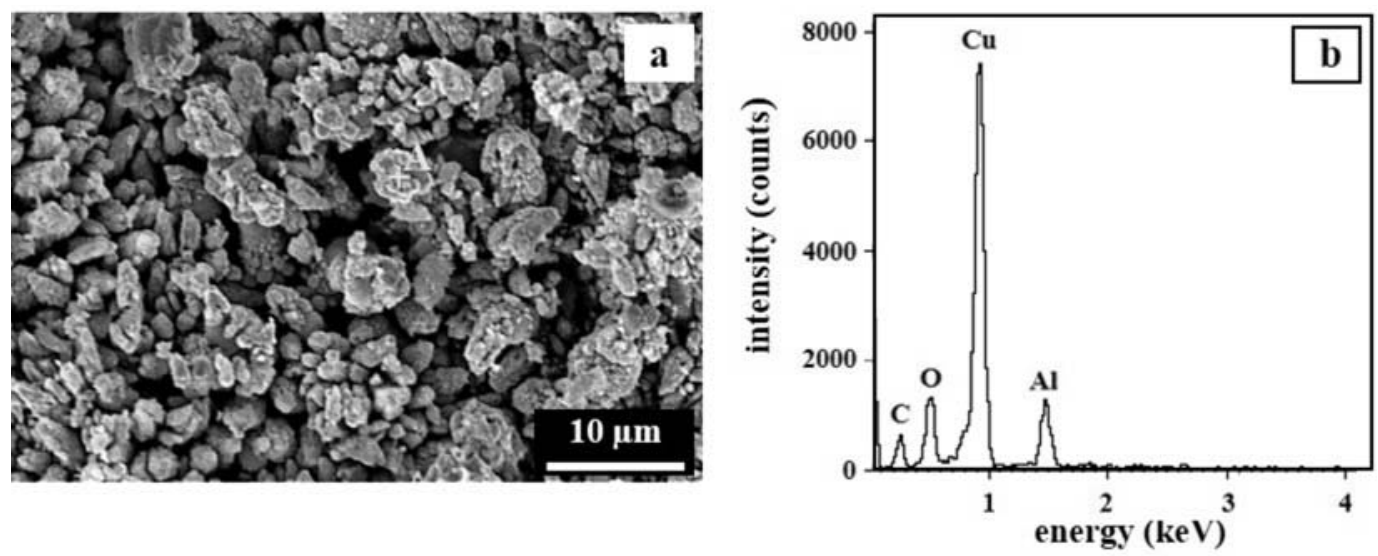

Fig. 7. SE micrograph of powder at tungsten electrode (a); EDS spectrum acquired from point A in Fig. 7a (b).

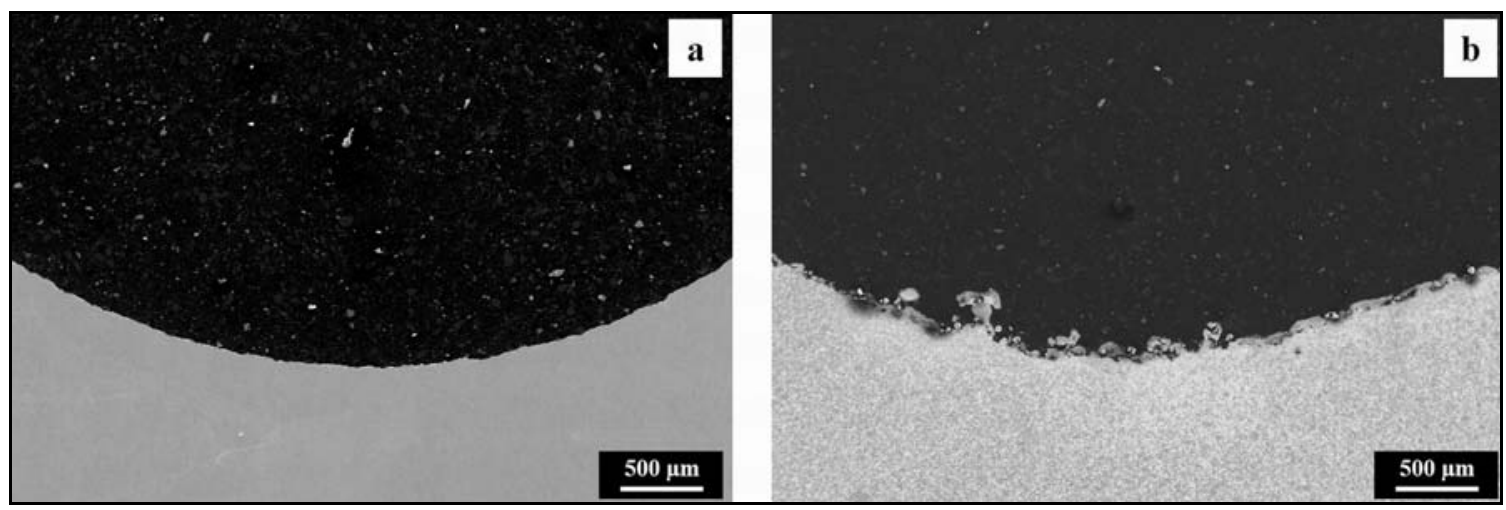

Fig. 8. SE micrographs of part of profile of crater central part for $\mathrm{Cu}$ (a) and $\mathrm{Cu} / \mathrm{Al}_{2} \mathrm{O}_{3}$ (b) after 200 spark cycles. 


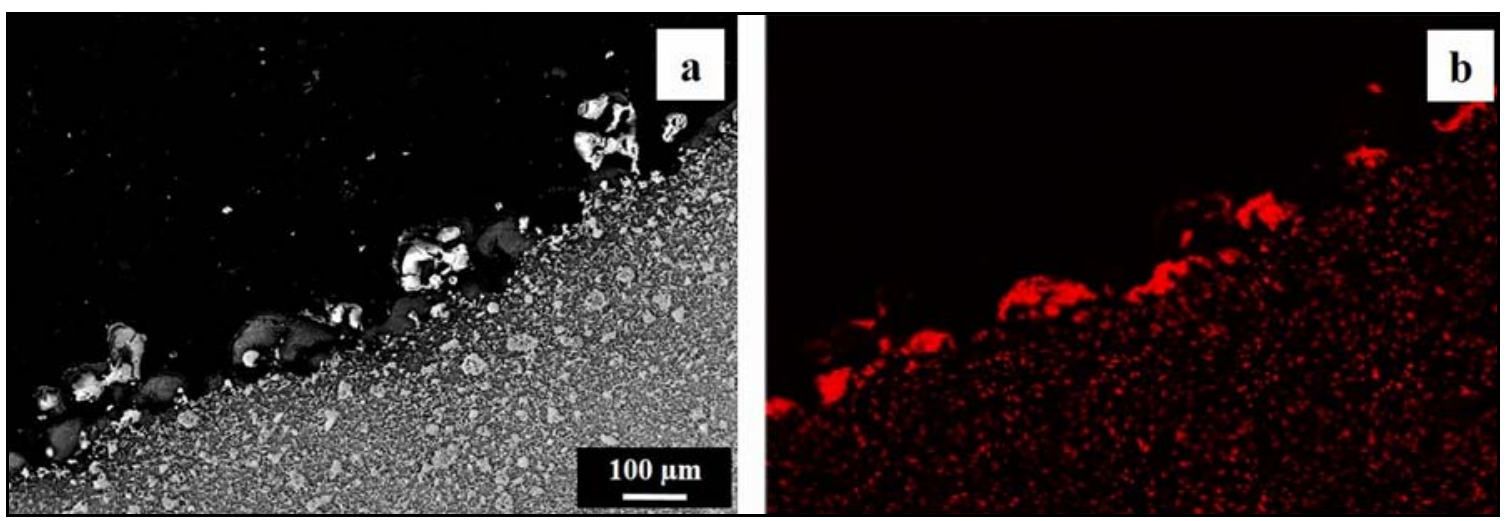

Fig. 9. The structure of the subsurface region in $\mathrm{Cu} / \mathrm{Al}_{2} \mathrm{O}_{3}$ crater (a) and corresponding X-ray mapping for $\mathrm{Cu}$ (b).
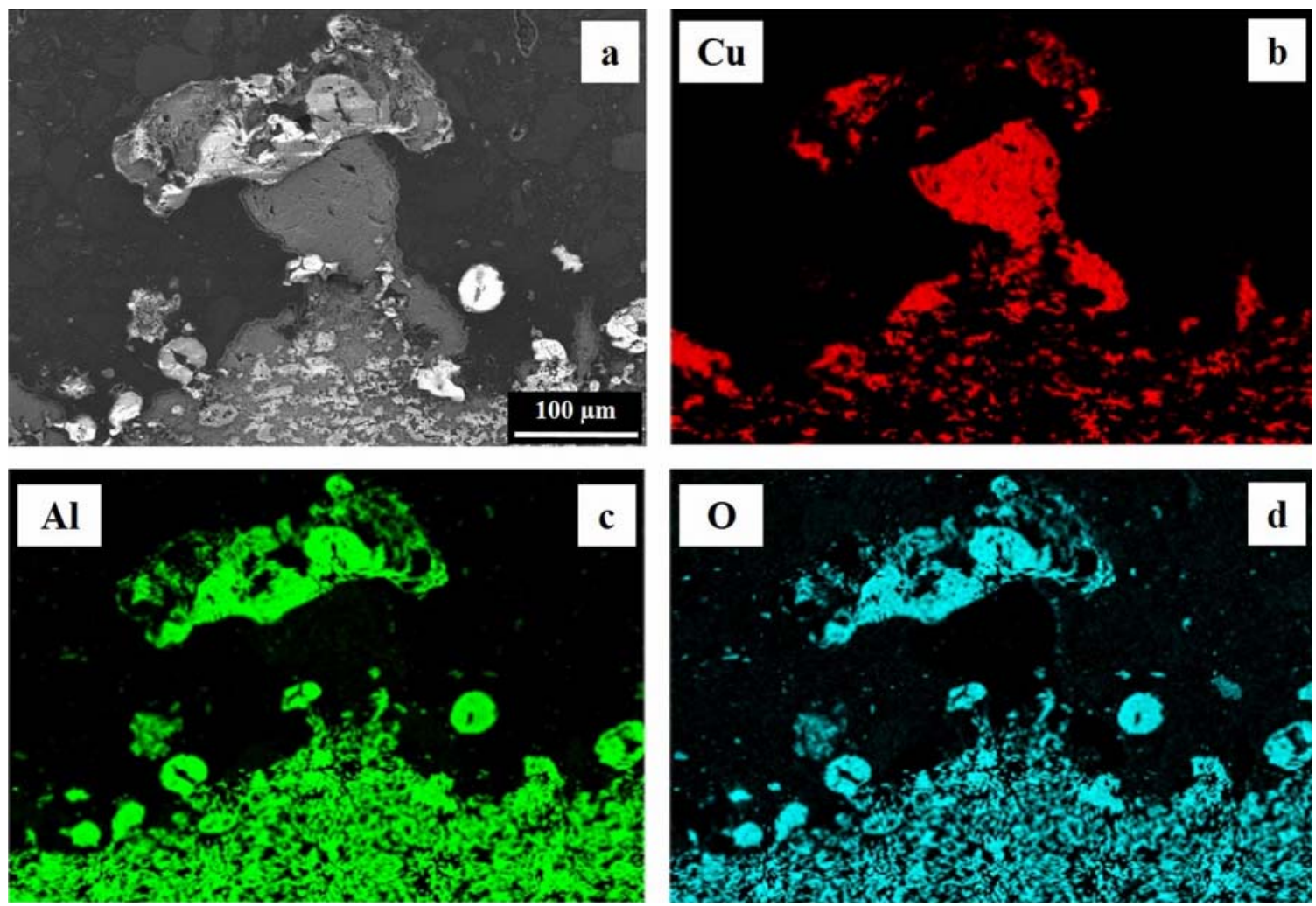

Fig. 10. SE micrographs of the microstructure of the subsurface region in $\mathrm{Cu} / \mathrm{Al}_{2} \mathrm{O}_{3}$ crater after 200 spark cycles (a) and corresponding X-ray mapping revealing the distribution of $\mathrm{Cu}(\mathrm{b}), \mathrm{Al}(\mathrm{c})$ and $\mathrm{O}(\mathrm{d})$.

interaction in sparks ablation resistance study of $\mathrm{Cu} / \mathrm{Al}_{2} \mathrm{O}_{3}$ composite.

For $\mathrm{Cu} / \mathrm{Al}_{2} \mathrm{O}_{3}$ composite, the typical feature was the creation of large rounded clusters on the surface by the effect of electrical sparks, Figs. 5b,d. It is observed that this region can be characterised by the phenomenon of remelting of both materials and also by the formation of big rounded grains on electrical sparks affected surface of $\mathrm{Cu} / \mathrm{Al}_{2} \mathrm{O}_{3}$ composite. An accumulation of agglomerates of $\mathrm{Al}_{2} \mathrm{O}_{3}$ particles from the disintegrated fragments of the $\mathrm{Al}_{2} \mathrm{O}_{3}$ ceramic preform in the central zone, which are sintered and/or remelted together with agglomerates of copper clusters created by multiple sparking processes can be assumed. The strong local melting was followed by rapid freezing to smooth the area.

It was observed that tungsten electrode tip was slightly coated after the electrical discharge tests performed on $\mathrm{Cu} / \mathrm{Al}_{2} \mathrm{O}_{3}$ samples. This indicates that small portion of that material randomly transfers to the tip of tungsten electrode. Cundal [25] has reported similar observations. Particles from $\mathrm{Cu} / \mathrm{Al}_{2} \mathrm{O}_{3}$ composite captured at the tip of tungsten electrode are presented in Fig. 7a. They are arranged in clusters 

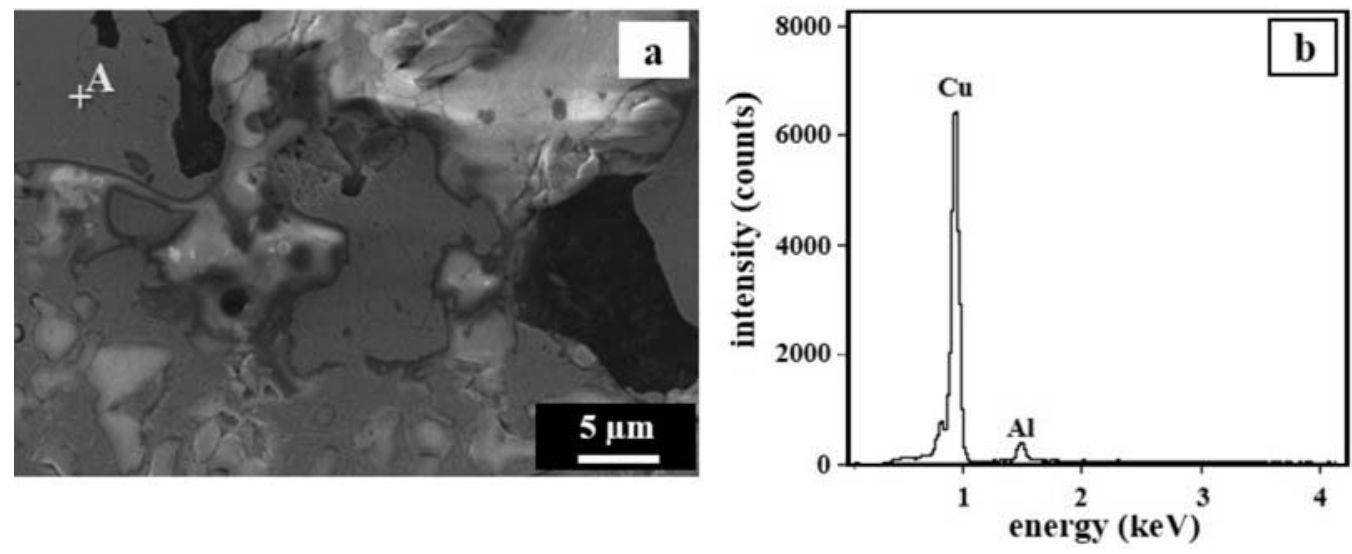

Fig. 11. SE micrograph of copper alloy clusters near the surface of the crater (a); EDS spectrum acquired from point A in Fig. 11a (b).

with size in the micrometre range. They contain $\mathrm{Cu}$, $\mathrm{Al}$, and $\mathrm{O}$ as confirmed by EDS in Fig. $7 \mathrm{~b}$.

After 200 spark discharge cycles, the craters of $\mathrm{Cu}$ and composite were cut into two parts, and their structure in cross-sectional views was observed. It appeared that both craters were symmetrical as presented in Fig. 8 a,b. EDS elemental mapping reveals that the surface of the composite crater is made up mostly of copper (Fig. 9). This is most probably because ceramic particles from alumina preform were, as a result of the impact of sparks on the composite in some regions of the crater, removed and copper was accumulated at the surface of the crater.

However, in some regions agglomerates with various forms and sizes appear (Fig. 10). Spheroidization of alumina particles obviously takes place, and irregular phases of intermixed composition are formed.

Some particles contain only $\mathrm{Cu}$ and $\mathrm{Al}$ as shown in Fig. 11. It is assumed that decomposition of alumina took place due to the interaction of sparks with $\mathrm{Cu} / \mathrm{Al}_{2} \mathrm{O}_{3}$. The $\mathrm{Al}$ released in this process subsequently alloyed $\mathrm{Cu}$. Actually no oxygen was present in this phase.

All this confirms that the process of spark interaction with the substrate is quite discrete, inhomogeneous on a local scale and yields irregular phases.

\section{Conclusions}

Conclusions can be summarised as follows:

- Spark discharge pulse formed in the spectroscopic analyser is a convenient method to study the ablation resistance of structural materials.

- Dependences of the amount of loss material on the number of electrical discharge analytical cycles for $\mathrm{Cu}-\mathrm{Al}_{2} \mathrm{O}_{3}$ composite material and pure copper were determined.

- The dependence of the volume of loss material on the number of discharges exhibits for both materials linear character.

- It appears that every discharge removes approximately equal amount of $\mathrm{Cu}$ and $\mathrm{Cu} / \mathrm{Al}_{2} \mathrm{O}_{3}$ composite.

- The ablation resistance of $\mathrm{Cu} / \mathrm{Al}_{2} \mathrm{O}_{3}$ composite exceeds that of $\mathrm{Cu}$ nearly 6 times.

$-\mathrm{Cu} / \mathrm{Al}_{2} \mathrm{O}_{3}$ composite failure mode includes the evaporation as well as melting of constituents.

- The interaction of sparks with the substrate is quite a discrete process strongly affected by local chemistry (composition). It results in irregular phases with respect to morphology as well as composition.

\section{Acknowledgements}

The authors gratefully acknowledge the financial support from the Slovak Grant Agency for Science under the project VEGA No. 2/0179/13.

\section{References}

[1] Knechtel, M., Prielipp, H., Müllejans, H., Claussen, N., Rödel, J.: Scripta Metall. Mater., 31, 1994, p. 1085. doi:10.1016/0956-716X(94)90531-2

[2] Derby, B., Xiao, P.,Webster, J.: Physica B, 248, 1998, p. 304. doi:10.1016/S0921-4526(98)00254-3

[3] Allen, B. C., Kingery, W. D.: Trans. Metall. Soc. AIME, 215, 1959, p. 30.

[4] Lange, F. F., Velamakanni, B. V., Evans, A. G.: J. Am. Ceram. Soc., 73, 1990, p. 388. doi:10.1111/j.1151-2916.1990.tb06523.x

[5] Travitzki, N. A., Claussen, N.: J. Eur. Ceram. Soc., 9, 1992, p. 61. doi:10.1016/0955-2219(92)90078-R

[6] O'Brien, T. E., Chaklader, A. C. D.: J. Am. Ceram. Soc., 57, 1974, p. 329. doi:10.1111/j.1151-2916.1974.tb10915.x

[7] Agrawal, P., Conlon, K., Bowman, K. J., Sun, C. T., Cichocki, F. R., Trumble, K. P.: Acta Mater., 51, 2003, p. 1143. doi:10.1016/S1359-6454(02)00519-0

[8] Hoffman, M., Skirl, S., Pompe, W., Rödel, J.: Acta Mater., 47, 1999, p. 565. doi:10.1016/S1359-6454(98)00367-X 
[9] Zhukov, M. F., Zasypkin, I. M. (Eds.): Thermal Plasma Torches. Design, Characteristics, Applications. Cambridge, International Science Publishing 2007.

[10] Ramli, M., Wagatsuma, K.: ISIJ Internat., 50, 2010, p. 864 . doi:10.2355/isijinternational.50.864

[11] Mesyats, G. A., Proskurovsky, D. I.: Pulsed Electrical Discharge in Vacuum. Berlin, Springer 1989.

[12] Rager, J., Flaig, A., Schneider, G., Kaiser, T., Soldera, F., Mücklich, F.: Adv. Eng. Mater., 7, 2005, p. 633. doi:10.1002/adem.200500025

[13] Behrisch, R. (Ed.): Sputtering by Particle Bombardment I. Berlin, Springer 1981.

[14] Anders, A., Anders, S., Gundersen, M. A., Martsinovskii, A. M.: IEEE Trans. Plasma Sci., 23, 1995, p. 275. doi:10.1109/27.402313

[15] Bahraini, M., Weber, L., Narciso, J., Mortensen, A.: J. Mater. Sci., 40, 2005, p. 2487. doi:10.1007/s10853-005-1980-1

[16] Gonzalez, E. J., Trumble, K. P.: J. Am. Ceram. Soc., 79, 1996, p. 114. doi:10.1111/j.1151-2916.1996.tb07888.x

[17] Travitzki, N.: Mater. Lett., 36, 1998, p. 114. doi:10.1016/S0167-577X(98)00012-3
[18] Winzer, J., Weiler, L., Pouquet, J., Rödel, J.: Wear, 271, 2011, p. 2845. doi:10.1016/j.wear.2011.05.042

[19] Kavecký, Š., Nagy, S., Stefánik, P.: Powder Metallurgy Progress, 15, 2015, p. 156.

[20] Popescu, I. V., Pencea, I., Anghelina, V. F., Branzei, M., Miculescu, F., Marcis, C., Petre, C.: Romanien Reports in Physics, 63, 2011, p. 823.

[21] Allen, K. L., Phillips, K.: Proc. R. Soc. Lond. A, 278, 1964, p. 168. doi:10.1098/rspa.1964.0053

[22] van Veldhuizen, E. M., Rutgers, W. R., Ebert, U.: Branching of Streamer Type Corona Discharge. http://www.ilp.physik.uniessen

[23] http://live.spectro.com/files/SPECTRO_ Whitepaper_Single_Spark_Evaluation_Technology.pdf

[24] Timko, H., Djurabekova, F., Nordlund, K., Costelle, L., Matyash, K., Schneider, R., Toerklep, A., Arnau-Izquierdo, G., Descoeudres, A., Calatroni, S., Taborelli, M., Wuensch, W.: Phys. Rev. B, 81, 2010, p. 184109. doi:10.1103/PhysRevB.81.184109

[25] Cundal, C. M., Craggs, J. D.: Spectrochemica Acta, 7, 1955, p. 149. doi:10.1016/0371-1951(55)80018-5 